\title{
Revista Etnias no Paraná: uma análise sobre as identificações da população paranaense
}

\author{
Raiane C. Ramirez dos Santos ${ }^{1}$
}

Resumo: Este texto, que se constitui em uma análise preliminar vinculada ao Programa Institucional de Bolsas de Iniciação Científica da UNIOESTE (PIBIC), financiado pela Fundação Araucária/SETI, aborda discursos presentes na revista comemorativa Etnias no Paraná, publicada em 1989 em razão do $28^{\circ}$ Festival Folclórico e de Etnias do Paraná. Nesta publicação são apresentados textos sobre oito grupos étnicos considerados como os que "contribuem valorosamente para o desenvolvimento do Paraná". Além destes, há também três textos de apresentação escritos pelo Governador do Estado na época, Álvaro Dias, pelo ex-secretário de Estado e da Cultura, René Ariel Dotti e pelo Diretor Presidente do Banco Banestado, daquele período, Carlos Antônio de Almeida Ferreira. Trata-se de um conjunto de discursos que constroem memórias e identificações étnicas para cada um destes grupos de migrantes e imigrantes que se fixaram no estado do Paraná a partir da segunda metade do século XIX.

Palavras-Chave: Revista Etnias no Paraná; Imigração; Identidade;

Abstract: This text, wich constitutes a preliminary analysis entailed to the Programa Institucional de Bolsas de Iniciação Científica from UNIOESTE (PIBIC), funded by Fundação Araucária/SETI, discuss about discourses presented at the commemorative magazine Etnias no Paraná, published in 1989 on the grounds of $28^{\circ}$ Festival Folclórico e de Etnias do Paraná. In this publication are presented texts about over

\footnotetext{
${ }^{1}$ Acadêmica do $4^{\circ}$ ano do Curso de História da UNIOESTE-Campus de Marechal Cândido Rondon. Bolsista do Programa Institucional de Bolsas de Iniciação Científica da UNIOESTE (PIBIC), financiado pela Fundação Araucária/SETI. Orientador: Prof ${ }^{\circ}$. Dr. Marcos Nestor Stein.
} 
eight ethnic groups considered as "worthily contribute to the development of Paraná". Besides these, there are also three introductory texts written by the Governor at the time, Álvaro Dias, by ex-Secretary of State and Culture, René Ariel Dotti and President Director of Banestado Bank, on that period, Carlos Antonio de Almeida Ferreira. This is a set of discourses that construct memories and ethnic identifications for each of these groups of migrants and immigrants who settled in the Paraná State from the second half of the nineteenth century.

Keywords: Etnias no Paraná magazine; immigration; identity;

O objetivo deste artigo é analisar os discursos presentes na revista Etnias no Paraná, publicada em 1989, em virtude do $28^{\circ}$ Festival Folclórico e de Etnias no Paraná. A partir desta fonte, é possível discutir como são construídas identificações étnicas para o estado e para a população paranaense, bem como memórias sobre a fixação de imigrantes no Paraná. Este estudo vincula-se ao Programa Institucional de Bolsas de Iniciação Científica da UNIOESTE (PIBIC), financiado pela Fundação Araucária/SETI.

A revista organiza-se em oito textos elaborados por integrantes dos grupos folclóricos da AINTEPAR (Associação Inter Étnica do Paraná), são estes: "Gaúchos no Paraná", "Os Germânicos no Paraná", “Os Holandeses no Paraná”, “Os Italianos no Paraná”, "Os Japoneses no Paraná”, "Os Poloneses no Paraná”, "Os Portugueses no Paraná" e "Os Ucranianos no Paraná", todos classificados como etnias. Além destes, há também três textos de apresentação escritos por Álvaro Dias, René Ariel Dotti e Carlos A. de Almeida Ferreira que no ano de publicação da revista (1989), ocupavam os cargos de Governador do 
Estado, Secretário de Estado e Cultura e Presidente do Banco Banestado, respectivamente.

O Festival Folclórico e de Etnias do Paraná é realizado anualmente desde a década de 1960, pelos integrantes da AINTEPAR (Associação Inter-Étnica do Paraná), no Teatro Guaíra, em Curitiba. A $28^{\circ}$ edição do evento, a que se refere à revista objeto desta análise, contou com o apoio do Governo do Paraná, Secretaria de Estado e Cultura, Coordenadoria da Ação Cultural, Divisão de Folclore e Artesanato com o patrocínio do Banco do Estado do Paraná (Banestado). Nossa análise sobre os discursos de identificação presentes na revista apoia-se em reflexões de Stuart Hall. Segundo ele, discursos de identificação, ao serem produzidos e divulgados, atendem a determinados interesses e apresentam uma determinada visão de mundo, portanto não são neutros.

É precisamente porque as identidades são construídas dentro e não fora dos discursos que nós precisamos compreendê-las como produzidas em locais históricos e institucionais específicos, no interior de formações e práticas discursivas específicas, por estratégias e iniciativas específicas ${ }^{2}$.

${ }^{2}$ HALL, Stuart. Quem precisa da identidade?. In: Identidade de Diferença: a perspectiva dos estudos culturais. Tomaz Tadeu da Silva (org.). Petrópolis, RJ: Vozes, 2000 
Nessa perspectiva, as narrativas sobre cada um dos grupos de migrantes e imigrantes presentes na revista remetem a um passado comum, que dá embasamento para a construção de suas identidades culturais, garantindo sua manutenção e continuidade. Nesse sentido, com base em Philippe Poutignat e Jocelyne Streiff-Fenart, partimos da perspectiva de que as fronteiras étnicas e/ou culturais não são naturais e nem estáticas. Com base nos estudos de Frederick Barth, tais autores afirmam que:

Há de convir, com Barth, que a etnicidade é uma forma de organização social, baseada na atribuição categorial que classifica as pessoas em função de sua origem suposta, que se acha validada na interação social pela ativação de signos culturais socialmente diferenciadores ${ }^{3}$.

Etnicidade, portanto, é uma categoria de classificação das pessoas em função da sua suposta origem, por meio de signos culturais socialmente diferenciadores. Dessa forma, a etnicidade é construída pela diferença.

A produção de discursos identitários para a população paranaense relaciona-se diretamente com uma série de políticas imigratórias, implementadas no estado do Paraná, desde sua emancipação, em 1853. Portanto, antes da análise da revista se faz

3 POUTIGNAT, Philippe; STREIFF-FENART, Jocelyne.Teorias da Etnicidade. Seguido de grupos étnicos e suas Fronteiras de Fredrik Barth. São Paulo: Fundação editora da UNESP, 1998.p.140. 
necessário apresentar, brevemente, um panorama das políticas imigratórias instituídas no Paraná, no período que compreende a segunda metade do século XIX. Sobre o contexto da emancipação político-administrativa do Paraná, o historiador Sérgio Odilon Nadalin (2001) afirma o seguinte:

[...] Enfim, é nessa conjuntura dominada pelas transformações relacionadas à extinção do tráfico o que pré-anunciava o fim do regime de trabalho escravo; a expansão do comércio exterior - que no Paraná era representado pelo desenvolvimento da economia do mate; a criação de um novo regime de terras, oriundo em parte da necessidade de modernizar o regime de propriedade no país e da luta política entre os defensores da "colonização" com imigrantes estrangeiros visando à substituição do braço cativo e aqueles que preconizavam a "colonização de povoamento"; e tendo ainda como pano de fundo o desenvolvimento de uma sociedade urbana originada do desenvolvimento de uma economia é que foi criada, no território anterior da $5^{\mathrm{a}}$ Comarca da Província de São Paulo, a Província do Paraná em $1853^{4}$.

A nova ordem liberal fundamentada na exportação, aliada a fatores como o aumento da população, remanejamento da mão de obra escrava para regiões cafeicultoras e desenvolvimento da urbanização, gerou uma crise na produção de gêneros de subsistência no Paraná, o que "levava a uma intolerável dependência dos paranaenses da

${ }^{4}$ NADAlin, S. O. Paraná: Ocupação do Território, Populações e Migrações. Curitiba: SEED, 2001.p. 71. 
importação de artigos do exterior e das outras províncias" 5 .

Devido a esta conjuntura, vários governantes desta província, com o argumento de que solucionariam o problema do abastecimento de alimentos e da baixa densidade demográfica no estado ${ }^{6}$, empreenderam ações que visavam atrair e estabelecer nacionais e imigrantes agricultores em seu território, organizados agrupamentos de pequenas propriedades, chamadas de colônias agrícolas, destinadas a produção de alimentos para subsistência.

Assim, os investimentos em colonização estavam entre as pautas principais de várias administrações que passaram por este estado, dentre as quais, evidencia-se a de Adolpho Lamenha Lins, presidente da província entre 1875 e 1877 . Sua política, também denominada de linismo, pretendia dar continuidade ao estabelecimento de imigrantes, adjetivados em seus discursos como "laboriosos e morigerados", e após pesquisar sobre os sucessos e fracassos das primeiras experiências com as colônias realizadas na província pelas gestões anteriores, pontuou algumas diretrizes para o novo sistema de colonização ${ }^{7}$ :

a- As colônias em hipótese alguma deveriam ficar situadas longe dos grandes centros consumidores;

b- Os núcleos coloniais deveriam ser localizados nos terrenos contíguos às estradas carroçáveis já

${ }^{5}$ Idem.

6 BAlHanA, Altiva Pilatti. Política Imigratória do Paraná. Revista Paraná Desenvolvimento, Curitiba, v. n.87, p.39-50, jan/abr., 1996.

${ }^{7}$ STEIN, Marcos Nestor. Colonos e Colônias Agrícolas no Paraná nos Séculos XIX e XX. I congresso internacional de História regional. Anais. Passo Fundo, UPF, 2011. 
existentes; Graciosa, Mato Grosso que ligava Curitiba aos Campos Gerais e a do Assungui, carroçável em alguns quilômetros para o norte de Curitiba;

c- Uma simples estrada vicinal, partindo da estrada tronco, seria suficiente para ligar os núcleos com a capital;

d- A verdade sempre deveria ser dita ao imigrante sobre a nova pátria em vez de poéticas descrições e exageradas promessas;

e- $\mathrm{O}$ transporte seria facilitado, evitando que o imigrante sofresse privação e maus tratos;

f- Os lotes de terra seriam oferecidos nas vizinhanças dos centros populosos e tornados comunicáveis entre si, por estradas de rodagem;

g- $\mathrm{O}$ colono poderia ligar-se à terra que habitava, pelo direito de propriedade, facilitando-se a aquisição da mesma;

h- Cada imigrante maior de 10 anos teria auxilio de fixação de 20\$000rs. e mais a mesma soma para compra de utensílios e sementes;

i- Após a fixação do imigrante, este seria logo empregado na construção das estradas da colônia, cessando então a alimentação por conta do governo;

j- Em cada colônia mais afastada da capital, seria edificada uma escola e capela;

k- A venda de sua produção agrícola seria possibilitada pela proximidade do mercado urbano, para que desta forma o imigrante não tardasse em pagar o valor da terra ao governo;

1- As novas gerações que houvessem aprendido a lidar com a terra e dominar as condições brasileiras, deveriam ser orientadas para o interior, evitando-se desta forma que as mesmas se urbanizassem; ${ }^{8}$

${ }^{8}$ WACHOWICZ, Ruy Christovam. História do Paraná. Curitiba-PR. Editora gráfica Vicentina,1995. p. 144 
Apoiado na trilogia colonização, indústria e capital, Lamenha Lins acreditava que, se aplicado da maneira correta, o modelo de colônias agrícolas solucionaria o problema do abastecimento de alimentos 9 . Neste sentido, propôs as diretrizes acima citadas, com intuito de evitar a evasão dos colonos para os grandes centros. O resultado disso foi a criação de várias outras colônias com este modelo e objetivo no decorrer de sua administração e das administrações seguintes que deram sequência a política de colonização. Além destes esforços de âmbito estadual, para o estabelecimento deste tipo de colonização, também houve investimentos de instância federal e de iniciativa privada.

Dessa maneira, de acordo com Nadalin, entre 1829 e 1911 instalaram-se no Estado 83.012 colonos estrangeiros ${ }^{10}$. Além dos estrangeiros, o território paranaense foi palco em que se fixaram pessoas de várias regiões brasileiras. O Oeste e Norte do Estado são exemplos deste tipo de ocupação ${ }^{11}$.

Esse processo foi acompanhado pela produção e difusão de discursos acerca destes migrantes e imigrantes, os quais eram qualificados positivamente, de modo a legitimar as iniciativas de colonização. Tais discursos foram, e por vezes ainda são, constantemente reproduzidos em documentos oficiais, textos

\footnotetext{
${ }^{9}$ SANTOS, C. R. A. Vida Material Vida Econômica. Curitiba: SEED, 2001. p. 78-79 ${ }^{10}$ NADALIN, S. O. Op. cit., p.77

${ }^{11}$ TOMAZI, Nelson D. Norte do Paraná. História e Fantasmagorias. Tese (doutorado em História) Curitiba: UFPR, 1997.
} 
acadêmicos, livros didáticos, na mídia, constituindo, assim, uma determinada memória sobre o processo de ocupação do Paraná. Isso pode ser lido na seguinte declaração proferida por Bento Munhoz da Rocha Netto, por ocasião das comemorações do Centenário de Emancipação do Paraná, em 1953:

(...) A vós todos um recado do Paraná para o Brasil: Isto aqui tem características regionais nossas, específicas. Temos manchas louras, gente loura de olhos azuis, mas que é tão brasileira quanto aquela que mais o seja. Temos aqui brasileiros de sobrenomes muito complicados, mas que se honram deste nosso Brasil, como nós outros que possuímos sobrenomes portugueses $^{12}$.

Neste trecho nota-se a intenção de criar uma identidade para o Estado do Paraná, na qual se ressalta a presença de imigrantes europeus, em detrimento de outros grupos que também ocuparam o território paranaense. Nesta e em outras narrativas sobre a população que compõe o estado é possível perceber que a mesma é retratada como sendo composta por vários grupos de diferentes origens, que convivem harmonicamente, compondo o chamado "mosaico étnico". Ademais, foram publicados muitos materiais comemorativos, que contribuíram para que esses discursos se cristalizassem, dentre estes está à revista

\footnotetext{
${ }^{12}$ NETO, Bento Munhoz da Rocha. Discurso pronunciado na sessão de instalação de um dos congressos comemorativos do centenário. In: Ilustração Brasileira. Edição Comemorativa do Centenário do Paraná. Ano XLIV, N. ${ }^{\circ} 224$. Rio de Janeiro: Edição da S. A. "O Malho". 1953. p. 19.
} 
Etnias no Paraná. Isto posto, iniciaremos esta análise pelos textos de apresentação da revista, escritos por integrantes da administração do estado, no ano de 1989. O primeiro texto, de autoria do ex-governador Álvaro Dias, declara:

O Paraná é um dos Estados da Federação de melhores possibilidades de bom sucesso nas mais diversas áreas de atuação social. Mercê de seu governoso povo e das condições de seu clima e de sua expressão econômica e social, a "terra de todas as gentes" merece um lugar destacado no cenário brasileiro e na perspectiva do futuro. Em função de um conjunto de qualidades de sua gente e de sua atual administração, é possível afirmar que "no Paraná o Brasil é levado a sério".

Diante de tão generosas qualificações, é gratificante para o Governo do Estado a constatação de que os eventos culturais, independentemente de sua natureza e extensão, caracterizam as faces da sensibilidade e da alegria da população, como é exemplo o Festival Folclórico e de Etnias. No ano em que o nosso país comemora o centenário da Proclamação da República, com destaque para seus heróis e mártires, o Paraná sente-se orgulhoso em patrocinar espetáculos tão enriquecidos de emoção como o festival folclórico e de etnias. Neste momento de grandes desafios para a vida nacional, o Paraná recebe carinhosamente os estilos e as expressões de outros povos para a confraternização de ideias e comunhão de esperanças ${ }^{13}$.

${ }^{3}$ Revista Etnias no Paraná. Curitiba: Governo do Estado do Paraná, 1989. 
As palavras do governador constroem uma narrativa que liga o presente e as perspectivas de futuro da população paranaense com a sólida base de um passado, comum a todos. Diferencia as condições climáticas, econômicas e sociais deste estado em relação aos outros estados brasileiros, ressaltando que o Paraná "merece um lugar destacado no cenário brasileiro", devido a esta diferenciação.

Cabe informar que a gestão de Álvaro Dias como governador do Estado do Paraná (1987-1991) implementou uma série de politicas relacionadas a preservação de patrimônio histórico e cultural, como podemos perceber por meio do decreto $\mathrm{N}^{\circ} 6.528$ :

Art. $1^{\circ}$ - A Secretaria de Estado da Cultura - SEEC, nos termos da Lei n. ${ }^{\circ} 8.485$, de 03 de junho de 1987 , constitui órgão de primeiro nível hierárquico da administração estadual, de natureza substantiva, e tem por finalidade coordenar e promover as atividades concernentes à área cultural.

Art. $2^{\circ}$ - Para o cumprimento de suas finalidades, à Secretaria de Estado da Cultura caberá:

I - a promoção e a difusão da cultura em todas as suas manifestações;

II - o estímulo e a orientação às atividades culturais dos Municípios;

III - a captação e a aplicação dos recursos públicos e privados, para a instalação e a manutenção de bibliotecas, museus, teatros e outras unidades culturais; 
IV - o apoio para a constituição de grupos voltados a todas as formas de manifestação cultural e artística;

V - a conservação e a ampliação do patrimônio cultural, compreendendo a preservação de documentos, obras e locais de valor histórico e artístico, além de monumentos, paisagens naturais e jazidas arqueológicas;

VI - a instituição e a manutenção de um sistema de informações relativo à planos, projetos e atividades desenvolvidos pela Secretaria;

VII - o incentivo à organização e à divulgação de estudos, pesquisas e quaisquer outros documentos de interesse para a cultura paranaense;

VIII - o incentivo à efetiva participação da comunidade na elaboração e proposta de planos, projetos e eventos de natureza cultural;

IX - o patrocínio de edição e reedição de documentos e estudos de especial relevância para a reconstituição de eventos de grande significado cultural;

X - a concessão de bolsas de estudo, auxílios e subvenções para pesquisas e investigações na área da cultura;

XI - o estímulo e o apoio à iniciativa privada paranaense, mediante concessão de auxílios e subvenções para a realização de atividades e eventos em sua área de atuação;

XII - a regionalização da atuação setorial a nível intra e interregional, bem como a criação de mecanismos de controle destas ações;

XIII - a promoção da especialização de pessoal nas diversas áreas da produção cultural. 
Parágrafo Único - A Secretaria de Estado da Cultura poderá apoiar a realização de eventos culturais em outros estados e países sempre que os mesmos contribuam para a difusão da cultura paranaense $\mathrm{e}^{14}$.

Este decreto só entrou em vigor no ano de 1990, mas pode-se observar que antes mesmo dele o governo empreendeu ações neste sentido como a publicação da revista e patrocínio ao evento. Além disso, em seu discurso, o ex-governador trata também do ano de centenário da proclamação da república como uma tentativa de relacionar o Paraná com o restante do país, mas mantendo ressaltadas as características que o diferenciam. Afirma também que se trata de um "momento de grandes desafios para a vida nacional" e que nesse contexto o Paraná se orgulha de receber diferentes "estilos e expressões de outros povos para a confraternização de ideias e comunhão de esperanças." Nota-se que o Paraná é representado como um lugar de convivência harmoniosa entre os vários povos que se fixaram em seu território, constituindo uma memória de um lugar onde não há conflitos.

René Ariel Dotti, então secretário de Estado e Cultura, também redigiu uma página de apresentação do evento. Nela afirma que uma política cultural de Estado que pretende desenvolver "princípios e regras" para as artes e para a literatura deve apoiar realizações como o

${ }^{14}$ BRASIL, PARANA. Decreto n ${ }^{\circ} 6.528$, de 25 de janeiro de 1990. Estabelece o Regulamento da Secretaria de Estado da Cultura - SEEC. Disponível em: http://www.patrimoniocultural.pr.gov .br/arquivos/File/Leis_e_Decretos/DEC6528.pdf.). Acessado em 20/07/2014 
Festival Folclórico e de Etnias no Paraná. Ressalta que a importância do evento, pois "traduz as expressões da música e da dança" de outros países que convivem e contribuem para o crescimento do estado. Deste texto destaca-se o seguinte trecho:

Sob outra perspectiva o Festival Folclórico e de Etnias vale como projeto de integração racial na medida em que, sem discriminações é construído por diversas variantes de cultura e de História. Por isso mesmo que o evento não tem caráter competitivo. Trata-se de um exemplo muito significativo, no momento histórico em que muitos países vivem em regime de guerra fria declarada e assumida ${ }^{15}$.

A ideia de "integração racial" é reforçada novamente negando os conflitos ao se referir à fraternidade na convivência desses grupos diferentemente do que estaria ocorrendo em outros países.

O terceiro e último texto de apresentação é de Carlos A. de Almeida Ferreira, que em 1989 era Diretor Presidente do Banco Banestado $^{16}$. Ele inicia o texto afirmando que uma empresa moderna deve ter comprometimento com o desenvolvimento da comunidade em que se encontra, e não apenas com lucros. Em seu texto, evidencia-se o seguinte trecho:

Revista Etnias no Paraná. Op. Cit.

${ }^{16}$ O Banco do Estado do Paraná, Banestado, era um banco estatal pertencente ao Paraná, privatizado e comprado pelo Banco Itaú em 2000. 
(...) $\mathrm{O}$ apoio ao festival segue esta linha de pensamento. É mais uma promoção que mostra o que o Paraná tem de mais rico e significativo nas suas tradições culturais. Somos afinal um imenso laboratório multirracial de 200 mil quilômetros quadrados onde convivem harmoniosamente, grande parte das etnias do planeta ${ }^{17}$.

O Paraná é identificado como um "imenso laboratório multirracional". O interessante é que esse laboratório não é caracterizado pela mistura entre todos estes grupos, mas sim pela sua convivência harmoniosa, circunstância que manteria as diferenças.

Nos três discursos é possível perceber que o Paraná é representado como um estado constituído de diferentes povos que preservam e devem continuar preservando as "tradições" de seus antepassados, tais quais eram no passado. Ou seja, cria-se uma memória coletiva a respeito da população do Paraná por meio de um discurso comemorador. Segundo Todorov, existem três tipos de discurso que organizam os vestígios do passado. $\mathrm{O}$ da testemunha, que se preocupa com o acontecimento em si, a partir de suas lembranças, podendo omitir, reter, deformar os acontecimentos. $\mathrm{O}$ do historiador, que tem o intuito de interpretar e analisar o passado, lançando-o um olhar crítico que não perde de vista sua subjetividade. E o do comemorador que tem

${ }^{17}$ Idem. 
como foco construir uma memória coletiva, ou seja, não tem compromisso com a "verdade" nem com os métodos ${ }^{18}$.

(...) a memória, no sentido de vestígios do mnésicos, é sempre e unicamente individual; a memória coletiva não é uma memória, mas um discurso que evolui no espaço público. Esse discurso reflete a imagem que uma sociedade ou grupo dentro da sociedade querem dar a si mesmo ${ }^{19}$.

Nessa perspectiva, tanto o historiador como o comemorador produzem discursos a serem apresentados na esfera pública. Contudo, o historiador submete os vestígios a exames e análises críticas, em busca de seus múltiplos significados, já o comemorador busca adaptar o passado aos seus objetivos presentes. Portanto, a memória coletiva deve ser entendida como historicamente construída por indivíduos em prol de determinados objetivos.

Em seguida, temos os discursos sobre os diferentes grupos, classificados como etnias. O primeiro grupo apresentado na revista são os "Os Gaúchos no Paraná", único texto que remete a um grupo "nacional".

Adotando esse amplo horizonte por morada e a atitude de livre do índio, os gaúchos viviam nas fronteiras do Rio Grande do Sul, Santa Catarina e Paraná, entre Entre Rios e Santa Fé, na Argentina e

${ }^{18}$ TODOROV, Tzevetan. Memória do mal tentação do bem. SP:ARX, 2002.

${ }^{19}$ Idem. 
no Uruguai. O gaúcho era o homem das fronteiras no Sul, com traços que hora remetiam aos portugueses e espanhóis, mas que também tinham a mestiçagem com o índio, em menor grau, e mais tarde com o negro.

Mais do que o tipo físico, o jeito de viver em razão do trabalho na campanha, com o gado vacum principalmente e depois o carneiro, montado a cavalo, portanto valores e atitudes do homem integrado à natureza aberta, o gaúcho passou a se constituir $^{20}$.

Neste sentido, o texto caracteriza como "gaúchos" todos aqueles que adotaram a "atitude livre do índio" que viviam "nas fronteiras do Rio Grande do Sul, Santa Catarina e Paraná” e que segue "valores e atitudes do homem integrado à natureza". Neste texto o "gaúcho" é caracterizado como resultante da mistura entre espanhóis, portugueses índios e negros. É importante destacar que os textos "Gaúchos no Paraná" "Os japoneses no Paraná” são os únicos a tratar da miscigenação como a efetiva mistura dos povos, e não como apenas uma "convivência harmoniosa" entre eles. Isso pode ser percebido no seguinte trecho:

Decorridos 80 anos da entrada dos primeiros japoneses que vieram no Kasato Maru, restam poucos nacionais do Japão em território paranaense. Em contra-partida, os brasileiros de origem nipônica que constituíram a geração nissei são muito numerosos e pela facilidade e preferência que

${ }^{20}$ Revista etnias no Paraná. Op. Cit. 
tiveram na miscigenação com brasileiros, já existe uma geração sansei, com poucos traços étnicos e culturais do Oriente ${ }^{21}$.

No texto referente aos "Portugueses no Paraná," percebe-se o objetivo de interligar a história do Paraná com a história do Brasil. Conforme o texto, antes da Proclamação da Independência, o Brasil era uma extensão de Portugal, desta forma, portugueses e negros não eram considerados "rigorosamente imigrantes". Verificam-se as noções de uniformidade e continuidade com relação à ocupação portuguesa.

No seguinte trecho, são atribuídas as seguintes características aos imigrantes portugueses: "São portugueses de origem humilde e camponeses dispostos a enfrentar qualquer trabalho, embora uma parte logo se dedique ao comércio". Considera inerente aos portugueses a aptidão para o comércio. Nos parágrafos seguintes do texto, afirma que a cidade de Paranaguá é o lugar do Paraná de maior herança lusitana e mais traços culturais portugueses. No último parágrafo, justifica que não há mais tantos nomes de origem portuguesa na cidade de Curitiba devido à "cosmopolitização" da cidade que os faz "ceder espaço" para os nomes de imigrantes de outras origens como poloneses, alemães, ucranianos, entre outros.

Aos outros grupos elencados na revista são destacados elementos materiais ou de sua personalidade que contribuíram para a constituição de um estado de sucesso e progresso, e que fazem de cada

${ }^{21}$ Revista etnias no Paraná. Op. Cit. 
grupo diferentemente especial. Isto pode ser constatado a partir dos trechos a seguir:

Sobre "os Italianos no Paraná":

Se alguém disser que foram os italianos que inventaram o gesto, o teatro, o canto, o vinho e as massas comestíveis não conhece história, mas pode conhecer bem os italianos. Afinal, essas coisas fazem parte da alma italiana, de sua cultura ${ }^{22}$.

Sobre "os Germânicos no Paraná":

[...] existem muitos indicadores da influência germânica em Curitiba, e que não foram exemplificados neste documento. É importante salientar consequentes influências nas mudanças de orientação artística, no estilo arquitetônico e a proliferação de edifícios com finalidades essencialmente comerciais, além das mudanças nas tradições religiosas e na própria dieta alimentar da população ${ }^{23}$.

Sobre "os Holandeses no Paraná":

Os Holandeses são os mais recentes imigrantes do Paraná. Aqui chegaram, a partir de 1911 e fixaramse no segundo planalto paranaense, na faixa de clima subtropical, e imprimiram sua elevada tecnologia nas atividades agropecuárias e industriais da

${ }^{22}$ Idem

${ }^{23}$ Idem. 
região ${ }^{24}$.

Sobre "os Poloneses no Paraná”:

(...) A imigração polonesa caracterizou-se em nosso país por ser fundamentalmente camponesa. Os camponeses poloneses transformaram as terras outrora incultas dos dois primeiros planaltos, em celeiros do Paraná. Introduziram novas técnicas agrícolas, novos instrumentos, novos produtos e uma mentalidade agrícola nova para a época. Mas o que mais caracterizou a imigração polonesa no Paraná foi a aceitação e difusão da carroça. No Paraná, esse fato gerou um ciclo intermediário entre o transporte em lombo de burro e o rodoferroviário ${ }^{25}$.

Observa-se, também, que há um silenciamento em relação a outros grupos que ocuparam o estado, pois é ressaltada apenas a ocupação europeia, asiática, e, quanto aos grupos de nacionais, apenas a sulista. Acerca do texto "os Ucranianos no Paraná”, há um importante ponto a ser destacado no seguinte fragmento:

(...) Sob a proteção da ONU, que sustentou materialmente, todos os refugiados, conseguiram os ucranianos a sua imigração para o continente americano.

A maior parte deles, seguiu para os Estados Unidos da América, Canadá, Argentina e outros países americanos. E no caso do Brasil, mais uma vez, o Paraná foi o Estado preferido.

${ }^{24}$ Idem.

${ }^{25}$ Idem. 
A pesar das tendências de absorção pela corrente majoritária do grupo eslavo, constituída pelos poloneses, conseguiram os ucranianos, manter sua identidade cultural. Para isso contribuíram não somente os imigrantes de após a Primeira Guerra Mundial, mas principalmente as Igrejas, tanto católica, quanto a ortodoxa, pois através do rito conseguiram manter a unidade lingüística. Ocuparam largo setor das atividades econômicas, conseguindo uma relativa prosperidade, sobre tudo nas frentes pioneiras do Paraná ${ }^{26}$. (Grifo nosso).

O trecho em destaque demonstra o "medo" deste grupo ter sua cultura misturada e/ou confundida com a de outro grupo eslavo. Isto nos faz questionar em que medida a convivência entre estes grupos era de fato "harmoniosa". Há certa preocupação marcar a diferença entre a "identidade cultural" dos ucranianos e dos poloneses. Neste sentido, a identidade da população paranaense construída nos discursos da revista é marcada pela diferença. A explicação de Kathyn Woodward acerca da relação entre identidade e diferença nos ajuda a compreender o trecho acima.

As identidades são fabricadas por meio da diferença. Essa marcação da diferença ocorre tanto por meio de sistemas simbólicos de representação quanto por meio de formas de exclusão social. A identidade, pois, não é o oposto da diferença: a identidade depende da diferença. Nas relações sociais, essas formas de diferença — a simbólica e a social — são estabelecidas, ao menos em parte, por meio de 
sistemas classificatórios. Um sistema classificatório aplica um princípio de diferença a uma população de uma forma tal que seja capaz de dividi-la (e a todas as suas características) em ao menos dois grupos opostos - nos/eles (por exemplo, sérvios e croatas); eu/outro ${ }^{27}$.

Podemos perceber no trecho da revista em destaque que tanto ucranianos como poloneses tem origem eslava, ou seja, descendem de imigrantes vindos da mesma região da Europa. No entanto, as diferenças são marcadas no texto em detrimento das semelhanças, dentro de padrões que podemos entender com o sistema classificatório, explicado por Kathryn.

Portanto, o conjunto das narrativas da revista apresenta cada "etnia" como um grupo com uma história comum e portador de características fixas, mesmo decorridos aproximadamente cento e trinta anos do início da (re)ocupação do estado até o ano de lançamento da revista, em 1989. Assim, torna-se extremamente necessário problematizar como são construídas historicamente as fronteiras que são usadas para estabelecer as identidades dos grupos no Paraná.

27 WOODWARD, Kathryn. Identidade e Diferença: uma introdução teórica e conceitual. In: SILVA, Tomaz Tadeu (org.). Identidade e Diferença: a perspectiva dos estudos culturais. Petrópolis, RJ: Vozes, 2012. p. 7 -72. 


\section{Referências:}

BAlHANA, Altiva Pilatti. Política Imigratória do Paraná. Revista Paraná Desenvolvimento, Curitiba, v. n.87, p.39-50, jan/abr., 1996.

BRASIL, PARANA. Decreto nº.528, de 25 de janeiro de 1990. Estabelece o Regulamento da Secretaria de Estado da Cultura - SEEC. Disponível em: http://www.patrimoniocultural.pr.gov.br/arquivos/File/Leis_e_Decretos /DEC6528.pdf. Acessado em 20/07/2014

HALL, Stuart. Quem precisa da identidade?. In: Identidade de Diferença: a perspectiva dos estudos culturais. Tomaz Tadeu da Silva (org.). Petrópolis, RJ: Vozes, 2000

NADALIN, S. O. Paraná: Ocupação do Território, Populações e Migrações. Curitiba: SEED, 2001.p. 71.

NETO, Bento Munhoz da Rocha. Discurso pronunciado na sessão de instalação de um dos congressos comemorativos do centenário. In: Ilustração Brasileira. Edição Comemorativa do Centenário do Paraná. Ano XLIV, N. ' 224. Rio de Janeiro: Edição da S. A. "O Malho". 1953. p. 19. 
POUTIGNAT, Philippe; STREIFF-FENART, Jocelyne.Teorias $d a$ Etnicidade. Seguido de grupos étnicos e suas Fronteiras de Fredrik Barth. São Paulo: Fundação editora da UNESP, 1998.p.140.

SANTOS, Carlos Roberto A. Vida Material Vida Econômica. Curitiba: SEED, 2001. p. 78-79

STEIN, Marcos Nestor. Colonos e Colônias Agrícolas no Paraná nos Séculos XIX e XX. I congresso internacional de História regional. Anais. Passo Fundo, UPF, 2011.

TODOROV, Tzevetan. Memória do mal tentação do bem. SP:ARX, 2002.

TOMAZI, Nelson D. Norte do Paraná. História e Fantasmagorias. Tese (doutorado em História) Curitiba: UFPR, 1997.

WACHOWICZ, Ruy Christovam. História do Paraná. Curitiba-PR. Editora gráfica Vicentina,1995.

WOODWARD, Kathryn. Identidade e Diferença: uma introdução teórica e conceitual. In: SILVA, Tomaz Tadeu (org.). Identidade e Diferença: a perspectiva dos estudos culturais. Petrópolis, RJ: Vozes, 2012. p. $7-72$. 